\title{
AUTONOMIA CIENTÍFICA DO DIREITO DE AUTOR"
}

\author{
Carlos Alberto Bittar \\ Professor Titular do Departamento de Direito Civil da Faculdade de Direito da USP
}

\begin{abstract}
Resumo:
Graças à evolução alcançada no presente século, o Direito de Autor consolidou sua autonomia científica, baseada na existência de objeto, de princípios, de conceitos e de regras diferenciados, constituindo-se em ramo autônomo do Direito Privado. O reconhecimento desse fenômeno pela Faculdade de Direito da Universidade de São Paulo, com a criação de um campo autônomo de estudos, contribuirão, de modo efetivo, para o aperfeiçoamento de técnicas próprias de controle, que permitirá constante harmonização da defesa dos interesses dos autores com os dos usuários e os da coletividade em geral.
\end{abstract}

\begin{abstract}
:
Thanks to the evolution that has characterized it in this century, Copyright has consolidated its scientific autonomy, based on the existence of specific subject, principles, concepts and rules. It is now a branch of Private Law. The recognition of this phenomenon by the Faculty of Law of São Paulo and the creation of an independent field of studies will contribute, in an effective way, to the development of specific techniques of control, which will allow the protection of author ' $s$ interests and the balance betweem users and the whole community ' $\mathrm{s}$ interests.
\end{abstract}

A questão da autonomia científica do Direito de Autor suscita, de início, a discussão sobre a clássica divisão do Direito em Público e Privado, já descrita por Modestino e por Ulpiano que, oriunda da diairesis grega, encontrou guarida em Roma, através do "Pai da Ciência Jurídica" Múcio Quinto Scévola, o Pontífice, consoante nos informa Alexandre Augusto de Castro Corrêa. Com a evolução havida nos estudos científicos, detectaram-se, depois, pelo processo de

* Texto da aula magna proferida no concurso em que o Autor obteve o grau de Professor Titular da Faculdade de Direito da USP, na área de Direito de Autor, e que ora dedica, em homenagem especial, ao eminente Mestre e Incentivador, Professor Rubens Limongi França. 
especialização, ramificações distintas em cada área, que vieram a formar núcleos próprios de regência de relações jurídicas especiais, ou, conforme Sérvio Suplício, sistemas de proposições deduzidas a partir de certas premissas assentes na doutrina (O Estoicismo no Direito Romano, p. 48 e 50).

Do Direito Romano à doutrina científica e desta às codificações, a divisão alcançou o mundo contemporâneo nos vários e distintos grupos de sistemas jurídicos existentes (o latino, o germânico e outros), como nos apontam os comparatistas, de que destacamos Arminjon, Nolde e Wolf (Traité de Droit Comparé, v. 1, p. 42); Edouard Lambert (La Fonction du Droit Civil Compare, p. 7 e ss.); René David (Les Grands Systèmes de Droit Contemporain, p. 83); e Lino Leme (Direito Civil Comparado, p. 10 e ss.). A distribuição está, ademais, consagrada na doutrina civilista, embasada em critérios definidos e universalmente reconhecidos pelos tratadistas, de que enunciamos: Ihering (Zweck im Recht, v. 1, p. 511 e ss.); Savigny (Traité de Droit Romain, 1855, p. 2 e ss.); Windscheid (Diritto delle Pandette, 1902, p. 3 e ss.); Démogue (Traité des Obligations en Géneral, 1923, v. 1, p. 3 e ss.); Josserand (Derecho Civil, trad., 1950, v. 1, p. 16 e ss.); Planiol e Ripert (Traité Pratique de Droit Civil Français, 1952, v. 1, p. 1 e ss.); Francesco Ferrara (Trattato di Diritto Civile Italiano, 1921, p. 2 e ss) Messineo (Manuale di Diritto Civile e Commerciale, 1947, v. 1, p. 11 e ss.); Henri de Page (Traité de Droit Civil Belge, v. 6, p. 806 e ss.); John Gilissen (Introdução Histórica ao Direito, trad., p. 13) e Franz Wieacker (História do Direito Privado Moderno trad., p. 10 e ss.). No Brasil podem, dentre outros, ser lembrados, Clovis Beviláqua (Códígo Civil Comentado, v. 1, p. 69 e ss.); Carvalho Santos (Código Civil Interpretado, v. 1, p 224 e ss.); Eduardo Espínola (Sistema do Direito Civil Brasileiro, p. 59 e ss.); Paulo Dourado de Gusmão (Introdução à Ciência do Direito, p. 120 e ss.). Esses critérios são os da natureza da relação regulada e do interesse predominante como bem salienta Maria Helena Diniz (Compêndio de Introdução à Ciência do Direito, p. 228 e ss. e 242 e ss.).

Com isso, contam, atualmente, os Direitos Público e Privado com inúmeras ramificações, dotadas de autonomia, em que sob premissas e sob ângulos diferentes são tratadas, de modo próprio, relações jurídicas especializadas, como, dentre outras, na área pública, as relações de caráter constitucional (D. Constitucional), administrativo (D. Administrativo) e financeiro (D. Financeiro) e, na área privada, as relações da vida comum (D. Civil), as mercantis (D. Comercial) 
e as decorrentes da criação e da utilização econômica de obras intelectuais estéticas (D. de Autor).

Ora, é o Direito de Autor, então, ramo autônomo do Direito Privado, tendo-se desgarrado do eixo comum, o Direito Civil, a partir da constatação de que rege relações revestidas de especificidade própria, e em que prepondera interesses privados, e sob ótica toda especial, onde mecanismos de proteção dos autores, como partes economicamente mais fracas, são inseridos na lei e contam, inclusive, com a participação do Estado em sua efetiva atuação. É tranqüila, na doutrina universal e em leis destacadas dos Códigos, essa colocação, com a chancela, aliás, dos grandes tratadistas da matéria, em que despontam, dentre inúmeros outros escritores, Eduardo Piola Caselli (Trattato del Diritto di Autore e del Contratto di Edizione, 1924); Henri Desbois (Le Droit d'Auteur en France, 1966); Stanislas D'Argoeuves (Du Droit Moral d'Auteur, 1924); Paolo Greco e Vercellone (I Diritti Nulle Opere del Ingegno, 1974); Nicola Stolfi (II Diritto di Autore, 1932); Luigi Di Franco (Proprietà Industriale, Letteraria ed Artistica, 1936); Tullio Ascarelli (Teoria de la Concurrencia y de los Bienes Inmateriales, trad., 1970); C. Mouchet e S. Radaelli (Derechos Intelectuales sobre Obras Literárias y Artísticas, 1948); Carlo Cristofaro (Trattado del Diritto di Autore e d'Inventore, 1931) e Stephen Ladas (The International Protection of Literary and Artistic Property, 1938).

Avulta, nesse contexto, o aspecto pessoal da relação entre autor e obra, salientado por Rubens Limongi França (Do Nome Civil das Pessoas Naturais, p. 380 e ss.) e que Morillot, cunhou, em 1872, com a denominação direito moral de autor. Complementa-se com as prerrogativas de ordem patrimonial que decorrem da comunicação da obra, conferindo, assim, estruturação toda peculiar ao Direito de Autor, como bem assinala Milton Fernandes (Pressupostos do Direito de Execução Musical, p. 5 e ss.). Pode-se, pois, com Ricardo Pereira Lira afirmar que o Direito de Autor é, como outros ramos jurídicos, técnica de organização social para a regência de certas e determinadas relações ("o moderno direito de superficie", p.1).

Preocupa-se esse Direito, em seu cerne com os vínculos jurídicos derivados da criação e da exploração econômica de obras literárias, artísticas e científicas, a nível interno e internacional, dada a extraordinária difusão, que a evolução da tecnologia permite às várias concepções de espírito situadas nos referidos domínios (pela imprensa, pelo rádio, pela televisão, pelo cinema, por 
satélites de comunicação, por via de laser e por outros tantos meios ou processos de comunicação).

Dirige-se, portanto, sob esquemas privados e estatais internos e, mesmo, sob instrumentos internacionais de ação (centrados, principalmente, na OMPI, Organização Mundial da Propriedade Intelectual, criada em 1967, na Convenção de Estocolmo, e ora com 139 países aderentes), para a disciplinação dos diferentes interesses envolvidos na utilização pública de obras de engenho. Por isso é que, desde os primeiros escritos aos trabalhos intelectuais do mundo da computação; da fotografia aos satélites de comunicação; do rádio ao sistema de laser, tem procurado o Direito de Autor proteger os titulares de direitos em suas relações com o mercado da comunicação e com o público em geral. Mas a construção do respectivo sistema demandou longos estudos e meditações, desde os trabalhos cientificos pioneiros de Édouard Laboulaye (Études sur la Propriété Literaire en France et en Angleterre, 1858); Eugène Pouillet (Traité de la Proprieté Literaire et Artistique, 1908); Alcides Darras (Du Droit des Auteurs, 1887) e Gustave Huard (Traité de la Proprieté Intelectuelle, 1906), na França; Moise Amar (Dei Diritti degli Autore di Opere Dell'ingegno, 1854), na Itália; Koehler (Das Autorrecht, 1888) e Gierke (Deutsches Privarrecht, 1895), na Alemanha; Edmond Picard (1877) e De Borchgrave (Évolution Historique du Droit d'Auteur, 1916); Mitteis (Zur Kenntnis des Literarisch - Artistischen Uhreberrechts Nachdem Osterreichischen, Gezetse, 1898); Tobias Barreto (Estudos de Direito, 1898, p. 459 e ss.); Samuel Martins (Direito Autoral: seu conceito, sua história e sua legislação entre nós, 1906 ) e Filadelpho Azevedo (Direito Moral dos Escritores, 1930), no Brasil; Browker (Copyright, its History and its Laws, 1912), nos EUA; Copinger (The Law of Copyright, 1927), na Inglaterra e Araki (A Lei sobre Direito de Autor, 1927), no Japão.

No extenso iter percorrido por esse Direito até a sagração da autonomia, já em nosso século, deve-se lembrar, para logo, a situação no Direito Romano, em que dois textos específicos continham disposições díspares: um, do Digesto, que permitia a aquisição de domínio através de pintura em tela alheia, ficando a tábua como res extincta (D. de adqui domin, v. $9, \S 2^{\circ}$ ), e, outro, das Institutes, que, em sentido contrário, outorgava ao proprietário do pergaminho a escrita nele feita por outrem (i., L.2, T. 1, § 33). Entendem, então, os comentadores que os romanos tinham noção dos direitos autorais, mas em plano abstrato, sem 
sanção concreta a não ser na defesa do respectivo aspecto moral, com respeito ao qual se considerava possível a invocação da actio injuriarum (conforme Scialojia: v. verbete "Diritti d'Autore" in Novissimo Digesto Italiano, v. 5, p. 694 e ss.; v. tb. Valerio De Sanctis, verbete "Diritto d'Autore" in Enciclopedia del Diritto, v. 4, p. 378 e ss.).

Dada a umbilical ligação entre o Direito de Autor e as técnicas de comunicação, foi somente com a invenção da imprensa, em 1436, por Guttenberg, que se aflorou, de modo concreto, no mundo jurídico, a problemática de um direito sobre reprodução de obra intelectual. A possibilidade de reprodução mecânica de textos (tecnologia nova à ocasião), levou os editores a solicitar e, depois, a obter a instituição de um regime de privilégio (monopólio) de exploração, submetido ao Conselho do Rei, para obras por eles lançadas ao público. Vigente por dez anos, impedia o uso da obra por concorrentes, garantindo-se, assim, mercado para o editor, que realizava, no fundo, verdadeiras criações artísticas sob a forma de livros e com textos, normalmente, de domínio público.

O primeiro texto legal sobre direito de cópia, ou copyright, foi expedido na Inglaterra, por Ana Stuart, atendendo a reclamos da comunidade intelectual britânica, em 1710, sob o título de Copyright Act, e conhecido como Estatuto da Rainha Ana. Concebida e materializada sob prisma objetivo, para proteção da obra como instrumento de desenvolvimento da cultura, essa fórmula foi seguida, mais tarde, pela Constituição Norte-Americana, de 1783 e pelo Federal Copyright Act, de 1790 (textos antecedidos pelos decretos dos Estados de Connecticut e Massachussets, de 1783).

O desenho definitivo do Direito de Autor como Direito voltado para a guarida dos criadores começou a ser traçado na França, como enfatizam, dentre outros, Marie Claude Dock (Étude sur le Droit d'Auteur, 1963, p. 20 e ss.) e Pierre Recht (Droit d'Auteur: une nouvelle forme de propriété, 1969, p. 19 e ss.), graças aos rasgos de luminosidade do advogado Héricourt, na defesa de interesses de intelectuais e de seus herdeiros em relações com os respectivos editores. Obteve decisões favoráveis do Conselho do Rei com respeito a obras de La Fontaine (1761) e de Fénelon (1777), até que, como profetizava Lamartine, sobre a obra intelectual pudesse ser contemplado um direito para o respectivo autor.

Com as leis francesas de 13 e 19 de julho de 1793, sobre execução e sobre reprodução de obras dramática e escritas, composições musicais, pinturas e 
desenhos, as quais atribuíram o direito de exclusividade aos criadores, ingressou a matéria no plano legislativo e como direito dos autores e, não mais de editores. Encerrava-se, assim, o ciclo dos monopólios, para inaugurar-se o da propriedade dos autores sobre suas concepções artísticas, literárias e científicas devidamente materializadas sob forma estética, ou seja, para sensibilização, ou para difusão ou transmissão de conhecimentos ao público.

Mister se faz, nesse passo, deixar assentado o pioneirismo legislativo do então Império do Brasil, que no Código Criminal, de 1831, contemplava delitos contra aspectos morais e materiais dos direitos autorais, a exemplo da codificação germânica e de sua doutrina pioneira, com Von Liszt e a conhecida ordenação de Nuremberg, confirmada pelo Senado de Frankfurt. Depois, na lei que instituiu os Cursos Jurídicos de São Paulo e de Olinda, de 11 de agosto de 1827, foram expressamente atribuídos direitos autorais aos lentes por suas preleções (art. $7^{\circ}$ ) (texto, aliás, reproduzido na parede da sala da Congregação da Faculdade de Direito da USP). Na doutrina, a par dos autores citados, podem ainda ser lembrados os especialistas Gustavo Baily (1930), Rodrigues Alves Filho (1940), Pedro Orlando (1944), Oswaldo Santiago (1946), Alberto Rocha Barros (1946), Pedro Vicente Bobbio (1952) e Antonio Chaves (1952).

A consolidação da autonomia, a par do brilhantismo de outros ilustres advogados, deveu-se à conjugação de vários elementos, a saber: a ação levada a efeito por associações de titulares de direitos; as contribuições da jurisprudência, o trabalho da doutrina; a edição de convenções internacionais sobre a matéria e as respectivas revisões, a começar pela União de Berna, de 1886; e a sucessiva expedição de leis nacionais especiais, destacadas das codificações.

Com efeito, enquanto editores se digladiavam no regime dos monopólios e os intelectuais assistiam, contristados, ao aproveitamento econômico de suas criações pelos editores, Richelieu e Beaumarchais começaram a concitar os autores, literatos, dramaturgos e compositores a reunir-se em entidades privadas de defesa dos interesses comuns, para a institucionalização de um direito de autor, ou direito sobre a criação e, não, sobre a reprodução da obra, como então se concebia. Sob esse signo, nasceram, em França, as duas primeiras associações, a SACD (1829) e a SACEM (1851) e, depois, no plano internacional, a ALAI (1878, presidida pelo imortal Victor Hugo), sendo o exemplo seguido por, praticamente, todas as nações civilizadas, inclusive o Brasil. Conscientizando os titulares e o 
mercado e demandando, judicial e extrajudicialmente, em prol dos direitos autorais, contribuíram, de modo decisivo, para a respectiva implementação prática.

$\mathrm{Na}$ jurisprudência, que teve a primazia de fazer valer, em concreto, direito moral de autor sobre obrigação regularmente contratada e paga, a primeira manifestação de relevo para o tema em debate foi a do arrêt Rosa Bonheur, em 1865, em que Tribunal francês assentou a tese de que, devido à mudança de concepção artística, podia um pintor recusar a entrega de obra sob encomenda. Tratava-se de retrato da bela mulher de certo barão, que o solicitara ao pintor, para ornamentação de sua residência, mas, realizada a obra - que mais exalçava os dotes da amada - não o teve o infeliz barão em seu patrimônio, diante da recusa do pintor que, no momento, havia repudiado a concepção artística com que o elaborara, resolvendo-se a lide com a recomposição patrimonial. Era o predomínio de direito personalíssimo sobre o de caráter obrigacional, com o qual iniciava o direito moral de autor sua caminhada em direção ao reconhecimento legislativo.

$\mathrm{Na}$ doutrina, há que se realçar a discussão, denominada por alguns autores, como "o debate do século XIX'" entre Edmond Picard - que em 1871 lançou a tese da existência de quarta categoria autônoma de direitos privados, a dos direitos intelectuais, depois consolidada em livro (Le Droit Pure, 1877, p. 103 e 117 e ss.) - e Kohler (ob. cit., 1888), defensor da inserção dos direitos autorais como direitos da personalidade, tese desenvolvida depois por Gierke (1895). Acrescer-se-iam esses direitos, consoante o jurista belga, aos direitos pessoais, reais e obrigacionais, da clássica divisão tripartite dos romanos, enquanto que a escola alemã se posicionava por sua qualificação no contexto referido, devendo-se, ainda, assinalar a posição da escola francesa, com Pouillet (1879) na vanguarda, que sustentava como de "propriedade imaterial" a classe em tela, na linha da codificação civil de sua terra. Envolveram-se, ainda, nessa problemática, Flourens (1872), Thaller (1902), Allfeld (1893), Borchgrave (1886), Dernburg (1900), Ulmer (1895), dentre outros doutrinadores, alguns com posições individualizadas (referidos na $R T$ 274/69, por Frederico José da Silva Ramos).

Com as convenções, ganhou amplitudes infinitas o Direito de Autor, bem como certa uniformização de tratamento, com o abandono definitivo da expressão "propriedade literária, artística e científica" diante do assentamento continuado de princípios e de regras básicas, que têm orientado os países interessados na elaboração da respectiva legislação interna. Desde o início, ao 
formar a União, firmaram os convencionais a diretriz de proceder a revisões periódicas do texto da Convenção de Berna, para adaptação às mutações tecnológicas, aos avanços científicos e artísticos e à própria evolução da doutrina científica. Com isso, tem sido possível ao Direito de Autor ajustar-se, continuadamente, aos progressos que as verdadeiras revoluções tecnológicas do século imprimiram ao mundo da comunicações.

Graças a elas, ademais, permitiu-se a inclusão do direito moral de autor no âmbito da Convenção, em função de brilhante defesa do advogado Hervieu, na revisão de Berlim, em 1908, e, mais tarde, na de Roma, de 1928, através do advogado italiano Eduardo Piola Caselli, que debateu com o germânico Zoll, quando se firmou a tese da incindibilidade, ou da unicidade do Direito de Autor, pela agregação anímica entre os direitos morais e os direitos patrimoniais, que empresta caráter todo especial a esse Direito. Essa discussão, que é o "debate do século $X X$ " na matéria possibilitou a consagração legislativa do Direito de Autor em diplomas autônomos, afastados, pois, das codificações, em verdadeiro "canto do cisne" da orientação fundada no direito real de propriedade. Estava, assim, cimentada a autonomia científica do Direito de Autor.

Completa o edifício a sucessiva edição de leis nacionais, com a sagração explícita do direito moral de autor, em sistema próprio de regência, como as leis italiana (1941) francesa (1957), sueca (1919), tcheca (1953), alemã (1901), austríaca (1936), mexicana (1963) e, mais tarde, a brasileira (1973), e em países de todos os continentes, submetidas às três orientações básicas: a do regime subjetivo (francês), direcionada para a defesa da pessoa do autor; a do esquema objetivo (anglo-norte-americano) dirigido para a obra, e a do regime coletivo, em que se mesclam conotações de cunho ideológico. Não escapou a essa linha de atuação o legislador brasileiro que, moldado na francesa, expediu a Lei $\mathbf{n}$. 5.988/73, a qual, como diploma central, regulamenta, entre nós, os direitos de autor e os que lhe são conexos (como os direitos dos artistas, dos intérpretes, dos executantes, dos produtores de fonogramas, dos organismos de radiodifusão e outros). Situa-se a nossa lei dentro dos textos que conferem um maximum de proteção aos autores, não obstante seja o Brasil país em desenvolvimento e que, em tese, poderia optar pelo sistema mínimo que a Convenção possibilita. Com isso, nivela-se nossa pátria aos grandes produtores e exportadores de cultura, protegendo, de modo adequado, os vários titulares de direitos. 
Forma, portanto, o Direito de Autor regime próprio de disciplinação juridica, contando, ademais, com organismos internacionais e nacionais (Conselhos ou Oficinas ou Registros) que atuam na normatização, na assistência e na fiscalização dos direitos reconhecidos. Constitui sistema ordenado e especial, no sentido colocado por Miguel Reale (Filosofia do Direito, 1962 ), Luis RecasénsSiches (Nueva Filosofia de la Interpretación del Derecho, 1973) e Carlos Maximiliano (Hermenêutica e Aplicação do Direito, $11^{\mathrm{a}}$.ed.), apto a oferecer soluções justas e coerentes para questões extranacionais, como as do Mercosul, e nacionais, que ora se debatem.

Na demonstração dessa autonomia, lembramos, com Alfredo Rocco (Principie di Diritto Commerciale, p. 161) - que procurava assentar a independência do Direito Comercial (primeira vergôntea a separar-se do Direito Civil) - que, para que determinado ramo do Direito seja conceituado como autônomo, faz-se necessária a existência de: objeto próprio; princípios específicos; normas especiais e conceitos e figuras próprias. Ora, enquadra-se, perfeitamente, o Direito de Autor a esse raciocínio. De início, conta com objeto próprio, que, como anotamos, se consubstancia na regulamentação das relações jurídicas oriundas da criação e da utilização econômica de obras de engenho. Vários princípios particulares inspiram, por sua vez, a respectiva textura, como, dentre outros, os de: limitação, no tempo, dos direitos de cunho patrimonial (no Brasil, basicamente, pela vida do autor e de certos sucessores; em outros países, com prazos menores, como os de cinqüenta, ou de vinte e cinco anos, e assim por diante); de intransmissibilidade e de perenidade dos direitos de caráter moral (que fazem dos direitos autorais os únicos direitos perpétuos: assim, quanto à paternidade, obras de talentos e de figuras geniais, como as de Aristóteles, Santo Tomás, Camões, Shakespeare, Michelângelo, permanecerão, indelevelmente, relacionadas a seus titulares, embora desaparecidos do mundo físico há séculos); da exclusividade de exploração do autor (que faz depender de sua prévia anuência qualquer uso público da obra com objetivo econômico); da reserva ao autor de direitos não compreendidos em contratos firmados (com a qual ficam na esfera do criador direitos não negociados, bem como direitos não existentes à época do contrato, como se decidiu em França, consoante J. G. Renauld, (Droit d'Auteur et Contrat d'Adaptation, 1955), quanto à ausência de autorização para sonorização de romance filmado em língua diversa, e, no Brasil, em disputa entre editores e herdeiros do 
célebre romancista Eça de Queiroz, quanto a não inclusão em contratos de cessão assinados antes de nova forma de comunicação das obras); e o da conseqüente interpretação restritiva das convenções sobre direitos autorais, quanto ao alcance, prazo, forma, modo de utilização e outros elementos do negócio. Outrossim, no atual contexto dos direitos autorais, figuram inúmeras e diferentes leis, tanto sobre direitos de autor, de artistas, intérpretes, executantes e outros titulares, bem como normas especiais nas leis sobre comunicações em geral. Por fim, diferentes conceitos e institutos peculiares compõem o âmbito do Direito de Autor, tais como, para simples ilustração, os de: autor; titular, originário e derivado (por sucessão, ou por via contratual); de obra primígena (independente) e derivada (nascida de outra); dos diversos contratos (de edição, de representação); das limitações ao exercício dos direitos (por força de exigências da cultura, das comunicações, do comércio e outras), dentre vários outros que, em nosso livro Direito de Autor, identificamos e comentamos.

Esses elementos são, enunciados, orgânica ou isoladamente, conforme o caso, pela doutrina especializada, que tem, ademais, produzido obras especificas, em que se defende a citada autonomia, ou se procura demonstrá-la, como parte do respectivo contexto. Referimo-nos, dentre outros, aos trabalhos de Jean Escarra (Droits Intelectuels, 1933); Isidro Satanowsky (Derecho Intelectual, 1933); Stig Stromholm (Le Droit Moral de l'Auteur en Droit Allemand, Français et Scandinave, 1966), Mario Are (L'Oggetto del Diritto di Autore, 1963), Claude Colombet (Grands Principes du Droit d'Auteur et des Droits Voisins dans le Monde, 1990) e Jose Antonio Vega Vega (Derecho de Autor, 1990).

Diversos fatores contribuiram, ainda, a par dos de índole jurídica, para o alcance da mencionada posição, tanto históricos, como culturais, políticos, científicos, econômicos e tecnológicos. Evidenciaremos, com a doutrina especializada, como Mario Fabiani ("Protezione Giuridica dell'Opera, sua Funzione Sociale como Strumento di Sviluppo della Cultura". em Diritto di Autore, 1976); Marie Claude Dock ("Il Diritto di Autore nei Presi in Via di Svilupo" em II Diritto di Autore 1976; Claude Masouyé ("Le Droit d' Auteur et le dévelopment" in Il Diritto di Autore 1977, p. 112 e ss.); Barbara Ringer ("Le Droit d'Auteur et l'avenir de la création intellectuelle" in Le Droit d'Auteur, 1976, p. 158 e ss.) e Michel F. Mayer "A decline of protection for creative rights" in RIDA, LXX/87, 1971), aqueles que, com mais freqüência, têm sido apontados: a insuficiência dos 
esquemas tradicionais de regência diante do conflito de interesses públicos e privados na área; o contínuo desenvolvimento da tecnologia e a inserção constante de novas formas de reprodução e de apresentação de obras estéticas; a complexidade e a especificidade das relações jurídicas, que envolvem direitos autorais, nos meios de comunicação; a necessidade de afirmação de cultura autóctone; a busca incessante do progresso econômico no setor de comunicações; a estimulação à pesquisa e ao trabalho literário, artístico ou científico; a necessidade de retribuição econômica aos titulares de direitos e o ideal de justa conciliação das prioridades nacionais com os interesses singulares envolvidos no uso e na difusão de obras estéticas.

Alcançada a independência científica - e, mesmo, didática, em certos países, como o nosso, em algumas Faculdades de Direito - vem o Direito de Autor enfrentando inúmeros desafios, que a constante evolução tecnológica lhe tem imposto. Enumeraremos as questões de maior vulto nesse verdadeiro embate entre a tecnologia e o Direito, para o equilibrio do uso das máquinas com a defesa dos nobres interesses dos criadores, as quais estão, há algum tempo, sendo discutidas no seio de organizações internacionais e mesmo nos países interessados: a reprografia (reprodução mecânica de obras); a "pirataria" (uso abusivo de criações alheias); a situação jurídica dos programas de computador, ainda em debate em certos países; a proteção dos titulares diante dos bancos de dados, dos meios eletrônicos de difusão de obras e do armazenamento em memórias artificiais; a radiodifusão por satélite (sistema cabo); a proteção a novas formas de fonogramas (como o CD), e a administração, ou gestão coletiva de direitos. Vislumbradas por futurólogos, como Júlio Verne (Viagem ao Centro da Terra) e outros, Arthur Clark (vários escritos) e Alvin Tofler (A Terceira Onda), os problemas gerados pelos avanços tecnológicos tem sempre posto, em evidência, o natural instinto de defesa e de preservação do homem que, quanto às nobres manifestações de seu intelecto, o Direito de Autor procura realizar.

Em projeção para o futuro, podemos afirmar que haverá contínua ampliação do espectro do Direito de Autor, com a inserção de novas formas de comunicação de textos, de imagens e de sons. Entendemos que o século XXI será o século do conhecimento e dos serviços, com a introdução, no cenário da relações humanas, de robôs inteligentes e de mecanismos de difusão de criações intelectuais 
(como os de transmissão a laser, que permitem comunicar texto completo de enciclopédia em segundos).

Ora, no equacionamento dos inevitáveis problemas que se oferecerão, presentes deverão estar os princípios e as regras especiais identificados e consagrados no âmbito do Direito de Autor, como instrumental hábil para a consecução dos fins expostos.

Daí, a necesșidade de especialização que nossa gloriosa Faculdade reconheceu, depois de longo gratificante trabalho que realizamos, desde os idos de 1976, quando defendemos nossa dissertação de Mestrado, intitulada Direito de Autor na Obra feita sob Encomenda. É que a formação de juristas, de pesquisadores e de estudiosos nesse campo constitui relevante contribuição que os meios acadêmicos podem prestar à sociedade para a defesa dos altos valores da cultura.

Com efeito, exigem as relações do setor tratamento específico, ditado por orientações que do sistema do Direito de Autor se podem extrair, na efetiva harmonização dos vários interesses envolvidos. Com isso se pode, paulatinamente, acompanhar o avanço tecnológico e, ao mesmo tempo, impor-se rédeas a incursões indevidas, dele oriundas, no circuito privado. Pode-se, pois, realizar o controle da tecnologia, apregoado por Hanah Arendt ( $A$ Condição Humana) e, na área mencionada, sob instrumentos específicos.

A linha básica dessa orientação está na efetivação da defesa dos titulares de direitos, sem prejuízo da difusão da cultura, a fim de que se concretizem os ideais máximos do homem nesse âmbito, quais sejam os de aperfeiçoamento intelectual dos seres e de integração e desenvolvimento das nações. Entendemos, a propósito, que terão proeminência no cenário internacional, os Estados que alcançarem o domínio do conhecimento. A criatividade será o fator decisivo e a respectiva estimulação, através de adequada proteção aos direitos autorais, via segura para a sua deteç̧ão, efetivando-se, assim, no fundo, a defesa da própria personalidade humana, enfatizada por Diogo Leite de Campos (Lições de Direito da Personalidade, p. 17), de sorte que o Direito de Autor assumirá, na sociedade do porvir, a condição de sistema magno de regência das relações humanas!... 